\title{
Discussion of the Ways in Which Our Ideas of Photography Have Changed Since the Introduction of Digital Photography
}

\author{
Dunmin Shi \\ Communication and media school of university of leeds \\ UK
}

\begin{abstract}
In digital era, digital technology resulted in a revolution of photography, which influenced the social practices, concepts of realism and the experience of photography. This article intended to study to what extent of the digital technology impact the photography, which include the revolution of technology, the transformation of concept of contemporary photography as well as the realism of photography. Besides, contemporary photography developing with network, which also changed the way of communication of contemporary photography.
\end{abstract}

Keywords-digital technology; photography; mobile photography

\section{INTRODUCTION}

"In present age, most new images made in the world will be captured, transmitted, and consumed digitally." (Biro, M., 2012) The development of digital technology resulted in a digital revolution in the field of photography, which involved every individual. With the popularization of digital camera and mobile phone not only more and more professional photographers became digital ones, but also amateurs take part in image production. We are all the witness of this historic transformation of photography over past 20 years. Digital technology influenced and changed photography from may perspectives. The progress of technology result in the promotion of the quality of images and work efficiency, which provided more possibilities for image production. In addition, digital techniques not only changed the way of image production, but also influenced the way of image communication and people's way of viewing. In digital era, the professional photographers are facing more challenges. The era that every individual could product images also put forward more requirements for professional photographers. Eventually, the relationship between digital photography and space, time, light, authorship as well as media made it clear that it represents significant differences to analog photography. And it also suggests that post-photographic era will be forever linked with others as a component in the interactive, networked interplay of a larger meta-media. (Ritchin, F., 2010)

This article will mainly discuss about the changes of photography influenced by digital techniques. The essay could be divided into three parts which are digital camera technology, the authenticity of digital photographs and the transformation of creation method in digital era.

\section{Digital CAMERA Technology}

\section{A. Image shooting process in digital age}

In this digital age, the development of digital technology plays a significant role in promoting the development of photography. There are much differences between digital photography and traditional photography, which include the skills of using DSLR camera, image-forming principles as well as the way of image output. The digital image technology innovated the traditional way of shooting. For example, people can see their photographs immediately after they pressing the shutter. Besides, people also have more possibilities to create their photographs in post production. For example, some post production software like Photoshop also provided photographers more possibilities to create imaginative photographs through changing tonality and photomontage...

\section{B. Storage and communication of digital images}

Within the last ten years, digital image techniques not only have changed the traditional creation process, but also changed the traditional way of storage and communication of photographs. For instance, the file transfer between digital camera and computer is based on data cable and memory card, which is more convenient and faster to store, copy and communicate. The form of the medium that has begun to emerge from this era of re-conception could be termed 'transient' photography which centers on virtual, changeable elements such as digital files that are produced, transmitted digitally and not printed but viewed on screens. (Bull, 2010)

\section{Mobile photography}

With the popularization of mobile phone, mobile photography became more and more popular. Mobile photography also enabled photography more contemporary characteristics such as transmittable, networked, viewed on screens and always easily open to manipulation. "Digital technologies not brought about the death of photography. There is more and more photography." (Lister, 2007, pp.251274.) Mobile photography enabled every individual in our society to become creators and consumers of images. Besides, 
mobile and tablet devices decreased the cost of image production and also changed the way of image communication to large extent. Specifically, people are used to view and share photographs on the screen instead of printing them.

\section{THE TRUTH OF PHOTOGRAPHY IN DIGITAL ERA}

\section{A. Fake photographs}

Photographs have been regarded as a kind of truly and intuitively communication media for a long term, which enabled images to be a kind of visual representation of reality. As a result, people use photographs to be the evidence of reality, especially in journalism. However, this situation has changed with the development of digital image techniques. Digital photographs are predicated on an indexical relation of image and referent in so far as light entering a camera is electronically processed to generate a code. However, as pixels are progressively transformed, this relation is weakened. (Edwards, S., 2006) The optical authenticity of photographs in digital era decreased due to the photography is a postproduction medium now. In recent years, some fake photographs processed by post-processed software appeared in the media, which result in people's question about credibility of journalism photography. Cooperated with network, it is difficult to distinguish the authenticity of these photographs which also lack of supervising.

\section{B. Social network}

In digital era, social network provided a communication platform for photographs. Individuals became we media. To be more specific, everyone could express their own point of view through social media. With the appearance of WIFI-enabled camera and mobile phone, the communication way of photographs has been changed. It is very convenient and fast to share photographs on social media, which promoted the information transfer efficiency to large extent and enabled more people to take part in social events. At the same time, it also resulted in some disadvantages.

First of all, since every individual could upload their photographs to the social network, social network broke the traditional photographs published process that make it difficult to control the quality of images. Secondly, social network brought information overload, however, the images have less and less meanings in post-photographic era. In postphotographic era, photography is no longer just the embalmer of time that André Bazin (André Bazin, 1967:14) once spoke of, but rather a more alive, immediate, and often transitory, practice/form. (Murray, 2008)

\section{The change of visual representation}

In the present age, every individual is involved in this digital revolution. Obviously, photographs are not the representation of reality to some extent. "For some critics, the developments in digital imaging in the 1980s and 1990s heralded the 'death' of photography and new modes of vision." (Wells,2003) The authenticity of photographs has become a big debate. The moment represented in the images could be fake due to people could compound and revise photographs or even delete them. Digital technology result in virtualization of visual culture.

The relationship between visual representation and reality is not corresponding in digital era. In present age, the characteristics of photographs are more ephemeral, inherently erasable and can be destroyed with little physical effort. More and more photographs may tend to reflect the virtual world. Consequently, in this culture environment, the journalism photography which value the importance of reflecting reality may have great impact. Kendall Walton said photographs are a kind of transparent media which is the copy of reality so that people could know the reality through photographs. (Kendall Walton, 2004) This visual communication theory enabled many media press to value photographs. However, the development of digital technology enabled people to critically think about the relationship between the representation of image and reality. In digital era, images not only represent reality, but also represent virtual world. In year of 1991, Mitchell put forward the idea of Post-Photography. In his point of view, images not relied on objective entity any more in postphotographic era. (Mitchell, 1994) There are full of virtual images in the media. The corresponding relationship between optical reality and image faded away. Debord also put forward the idea of the society of spectacle. He thought the whole life is a kind of spectacle. Everything that exist before became pure representation which was image. In present age, images have already become a kind of power like economic power and political power. Contemporary visual culture was not regarded as the reflection of the world we live. Instead, images also create this world. (Debord, 2004) "In the post-photographic era, we must face once again the ineradicable fragility of our ontological distinctions between the imaginary and the real." (Mitchell, 1994)

At the same time, when creator take photographs not in order to reflect reality, the cognizance of viewers about images also changed. The level of their credibility to photographs reduced, which influenced the communication between image producers and viewers. Consequently, the viewers became more and more particular.

\section{THE TRANSFORMATION OF PHOTOGRAPHY CONCEPT}

In this digital era, the popularity of digital camera and mobile phone enabled more and more people to become the creator of photographs. And digital technology also provided image producer more new concept of creation.

Recently, Canon Company held a photography competition for Chinese university students majoring in photography which united 94 university students who from 16 different universities Their photographs are typical sample to study the trend of creation concept of young generation photographer. One the one hand, these students are going to work in this field and professional photographer could represent the main stream of image production due to they are the constitutor and performer of industry standard. On the other hand, these young photographers grew up in digital era, their concept of photography could represent the future of photography to some extent. Consequently, to study how these young photographers take advantage of digital image techniques to create has 
significant meaning for studying changes and tendency of field of contemporary photography.

The writer will analyze these competition works through data statistics. Since the competition set up a relatively high level for participants, these universities could represent the highest level of higher education of photography. And these works have been selected by their tutors so that these final competition works have good quality which could represent the level of future professional photographers. In addition, Canon Company required every participant to use same equipment, have same theme and finish within two days. These requirements provided us a platform to compare.

\section{A. The change of creation concept}

The main creation concept of this competition could be divided into two categories. The first one is reflecting the real world. To be more specific, it is not mean that image itself is objective and real. The characteristic of these words is objective existence instead of virtualization. And the second category is not reflecting reality, which take advantage of digital camera to pick-up information and reflect some virtual image that does not exist in reality. We can see from the data below that there are 43 participants belong to the first category accounting for $45.7 \%$. And there are 51 participants in the second category which occupied 54.3\%. And another chart showed that in the second category, there are 38 photographer used models and express their own thoughts through hypothetical role.

This statistic result may suggest that in China the creation trend of young generation photographers could be classified into two ways. The first way is that respect the characteristics of photography equipment to record the real world. However, another way is to regard photography techniques as a kind of assistive tool to create the imaginary world and then combined with digital post-process means. Obviously, the young generation photographers tend to make photographs instead of taking photographs to some extent.

\section{B. The change of creation method}

The sample data also can illustrate the transformation of Chinese young generation photographers' creation method. Firstly, it can be seen that these competition works have colorization tendency. Due to there are only 12 participants use black and white images which occupied $12.7 \%$. It may suggest that the new generation photographers influenced by television and commercial community so that they prefer to use color to express themselves.

Secondly, the data showed a tendency of subjectivization. We can see from the sample that most photographers not in order to express reality even for those who are in the first category. It is showed that there are 10 photographer take advantage of slow shutter to create in the first category. In addition, there are many photographs take advantage of lyric scenery to express themselves. For example, a photographer said he want to use Palace Museum to express himself. Finally, it seems that there are only 15 participants reflected the reality objectively which account for $16 \%$.
Thirdly, these sample also showed a digital trend, which means the young generation photographer valued the use of digital method in their image production process. We can see from the statistical result that there are 18 photographers using digital image techniques to create photomontage. Besides, there are 5 photographers changed the realistic color. For instance, one work is about worker portrait and the photographer used apochromatic way to express, which only remained local color. Consequently, there are 23 works more rely on digital post process rather than prophase shooting which occupied $25 \%$.

\section{THE RESULTS OF DATA ANALYSIS}

In present age, the purpose of image production for young generation photographers is not to convey reality. And to provide the evidence for reality may not their attitude of photography. They may prefer to abstract the elements from reality to express their point of view and cognition behind the reality rather than record the real world as discoverers. (Ewing, W.A., 2010)

It may suggest that the young generation photographers are more subjective and they long for expressing themselves. They ignored the decisive moment to some extent and more tend to make the moment. For example, more and more photographers prefer to achieve perfect composition of the picture through control model. In addition, they are more familiar with digital method. It seems that with the popularization of photoshop in every family, people are not only the consumer of images but also the creators of images. In the present age, it has become a widespread phenomenon that photographers could revise their photographs arbitrarily. The color of sky and ocean in the photographs are not their original color, which has been adjusted to the color that the photographers want it to be. (Ewing, 2010)

\section{CONCLUSION}

In conclusion, the development of digital technology decreased the cost of taking photographs and promoted work efficiency as well as usability, which result in the digital revolution in the field of photography. From the perspective of technology, the development of photography boosted the quality and communication efficiency of photographs and innovated the way of creation for photography. At the same time, photography has become a kind of post processed medium in digital age. Consequently, the post-processed method provided more possibilities for creators to express their subjective world, which form the new trend of image production. Photographs are not the representation of reality to some extent in digital era.

Obviously, digital technology even changed our visual culture and this trend also require photographers to adjust the new changes.

\section{REFERENCES}

[1] Bazin, A., 1967. What Is Cinema? vol. and trans. Hugh Gray (Berkeley, CA: University of California Press, 1967), p.14.

[2] Biro, M., 2012. From Analogue to Digital Photography: Bernd and Hilla Becher and Andreas Gursky. History of Photography, 36(3), pp.353-366. 
[3] Bull, S., 2010. Photography (Abingdon.

[4] Debord, G., 2004. The Society of the Spectacle. 1973. Reprint, New.

[5] Edwards, S., 2006. Photography: a very short introduction. Oxford University Press.

[6] Ewing, W.A., 2010. ReGeneration2: Tomorrow's Photographers Today;[Ueli Alder, Yann Amstutz, George Awde...; on the Occasion of the Exhibition of the Same Name: Musée de L'Elysée, Lausanne, 18 June-26 September 2010; Rencontres D'Arles, 3 July-19 September 2010; Michaelis School of Fine Art, University of Cape Town, 27 July-3 September 2010; Galleria Carla Sozzani, Milan, 6 November 2010-10 January 2011; Centre Gallery, Miami Dade College, 11 November-18 December 2010; Aperture Foundation, New York, 20 January-17 March 2011]. Thames \& Hudson.
[7] Lister, M., 2007. A Sack in the Sand Photography in the Age of Information. Convergence: The International Journal of Research into New Media Technologies, 13(3), pp.251-274.

[8] Murray, S., 2008. Digital images, photo-sharing, and our shifting notions of everyday aesthetics. Journal of Visual Culture, 7(2), pp.147-163.

[9] Mitchell, W.J., 1994. The reconfigured eye: Visual truth in the postphotographic era. Mit Press.

[10] Ritchin, F., 2010. Envisioning Digital-Failing to Harness the Web's Visual Promise. Nieman Reports, 64(1), p.6.

[11] Smith, K.L., Moriarty, S., Kenney, K. and Barbatsis, G. eds., 2004. Handbook of visual communication: Theory, methods, and media. Routledge.

[12] Wells, L., Barthes, R., Berger, J., Rosler, M. and Sontag, S., 2003. The photography reader. Routledge. 